\title{
Bactérias fixadoras de nitrogênio e molibdênio no cultivo do amendoim em solo do Cerrado
}

\author{
Diego Muniz da Silva Santos ${ }^{1}$; Aécio Bush ${ }^{1}$; Elijanara Raissa da Silva1; Alan Mario Zuffo \\ Fábio Steiner ${ }^{1}$
}

${ }^{1}$ Universidade Estadual de Mato Grosso do Sul - UEMS, Unidade Universitária de Cassilândia, Cassilânida, Mato Grosso do Sul, Brasil. E-mail: diegomunizbbr@gmail.com, raissa@agronoma.eng.br, alan_zuffo@hotmail.com, steiner@uems.br

Recebido: 03/09/2017; Aceito: 26/10/2017.

\section{RESUMO}

O uso de práticas agrícolas sustentáveis que otimizem a fixação biológica de nitrogênio (FBN) pela cultura do amendoim são importantes para assegurar elevados níveis de produtividade. Portanto, neste estudo objetivou-se avaliar a eficiência da aplicação de molibdênio e da coinoculação das sementes com Bradyrhizobium japonicum e/ou Azospirillum brasilense na nodulação, no crescimento e na partição de matéria seca das plantas de amendoim (Arachis hypogaea L., cv. IAC Tatu ST). As plantas foram cultivadas em vasos de 5,5 L preenchidos com um solo arenoso do Cerrado e mantidas em casa de vegetação. O experimento foi disposto no delineamento de blocos casualizados em um esquema fatorial $2 \times 4$, com quatro repetições. Os tratamentos constituíram da aplicação (+Mo) ou não de molibdênio $(-\mathrm{Mo})$ na proporção de $10 \mathrm{~g}$ para $50 \mathrm{~kg}$ de sementes e de quatro tratamentos de inoculação: i) controle (sem inoculação); ii) inoculação com Bradyrhizobium japonicum; iii) inoculação com Azospirillum brasilense; e, iv) coinoculação com B. japonicum e A. brasilense. Os resultados evidenciaram que a coinoculação das sementes com $B$. japonicum e A. brasilense melhorou a nodulação e a produção de matéria seca das plantas. Estes resultados indicam que a prática de coinoculação pode proporcionar sustentabilidade para o sistema de produção de amendoim por melhorar a fixação biológica de nitrogênio e o crescimento das plantas. A aplicação de Mo nas sementes não alterou a nodulação e o crescimento das plantas de amendoim.

Palavras-chave: Arachis hypogaea L, inoculação, fixação biológica de nitrogênio, nodulação, micronutriente.

\section{Nitrogen fixing bacteria and molybdenum in peanut cropping on Brazilian Cerrado soil}

\section{ABSTRACT}

The use of sustainable agricultural practices that optimize the biological nitrogen fixation (BNF) by peanut crop are important to ensure high levels of productivity. Therefore, the objective of this study was to evaluate the efficiency of molybdenum (Mo) application and co-inoculation of seeds with Bradyrhizobium japonicum and/or Azospirillum brasilense on nodulation, plant growth and dry matter partitioning of peanut (Arachis hypogaea L., cv. IAC Tatu ST). The plants were grown in $5.5 \mathrm{~L}$ pots filled with Cerrado sandy soil under greenhouse conditions. The experiment was arranged in a randomized block design in a $2 \times 4$ factorial schemes, with four replications. The treatments consisted of the application (+Mo) or not of molybdenum (-Mo) in the proportion of $10 \mathrm{~g}$ to $50 \mathrm{~kg}$ of seeds and four inoculation treatments: i) control (without inoculation); ii) inoculation with Bradyrhizobium japonicum; iii) inoculation with Azospirillum brasilense; and, iv) co-inoculation with B. japonicum and A. brasilense. The results showed that seed co-inoculation with B. japonicum and A. brasilense improved the nodulation and dry matter production of the plants. These results indicate that the co-inoculation practice can provide sustainability for the peanut production system by improving BNF and plant growth. The application of Mo in the seeds did not alter the nodulation and the growth of the peanut plants.

Key words: Arachis hypogaea $\mathrm{L}$, inoculation, biological nitrogen fixation, nodulation, micronutrient. 


\section{Introdução}

O molibdênio (Mo) é um micronutriente essencial para o crescimento das plantas, especialmente para as espécies leguminosas, como o amendoim (Arachis hypogaea L.), que são capazes de fixar $\mathrm{o} \quad \mathrm{N}_{2}$ atmosférico. A importância deste micronutriente devese à sua participação como constituinte das enzimas nitrogenase, responsável pela fixação biológica do nitrogênio $(\mathrm{FBN})$ por rizóbios, e da nitrato redutase, responsável pela redução do nitrato $\left(\mathrm{NO}_{3}{ }^{-}\right)$a nitrito $\left(\mathrm{NO}_{2}^{-}\right)$(KERBAUY, 2012). Desta forma, tanto a FBN como a assimilação do $\mathrm{N}$ são seriamente afetadas pela deficiência de Mo no solo (LI et al., 2013). De fato, os sintomas de deficiência de Mo expressam-se em condições de deficiência de $\mathrm{N}$, apresentando amarelecimento das folhas mais velhas e possíveis necroses marginais com acúmulo de nitrato (QUAGGIO et al., 2004).

Os solos do Cerrado, na sua maioria, caracterizam-se por serem ácidos e, nestas condições quando o $\mathrm{pH}$ é inferior a 5,0, a quantidade de Mo disponível para as plantas é extremamente baixa, resultando na deficiência desse micronutriente no solo (MENGEL; KIRKBY, 2001). Como o Mo é exigido em pequenas quantidades pelas plantas, este micronutriente pode ser aplicado via sementes. Quaggio et al. (2004) constataram que a aplicação de Mo via semente resultou em aumentos significativos no teor de $\mathrm{N}$ nas folhas de amendoim e, consequentemente, melhorou o rendimento de grãos da cultura. Portanto, o Mo tem sido considerado um dos micronutrientes de maior resposta para a cultura do amendoim em solos tropicais.

$\mathrm{O}$ amendoim (Arachis hypogaea L.), por ser uma espécie leguminosa, apresenta a característica de associação com bactérias fixadoras de $\mathrm{N}$ (Bradyrhizobium sp.), o que lhe permite eficiência no processo de absorção desse nutriente. No entanto, a prática de inoculação com Bradyrhizobium (rizóbio) nos cultivos comerciais de amendoim no Brasil não tem sido muito comum, principalmente, devido a ampla faixa de rizóbios nativos presentes nos solos tropicais com capacidade de colonizar as raízes de amendoim (THIES et al., 1991). Apesar dessa constatação, em algumas situações, como em áreas de primeiro cultivo de plantas leguminosas, onde não existem populações consideráveis de rizóbio no solo, a prática de inoculação tem sido recomendada com a finalidade de aumentar o rendimento de grãos da cultura, como evidenciado por Crusciol e Soratto (2007).

Considerando as limitações da FBN do amendoim inoculado com Bradyrhizobium, a utilização de rizobactérias promotoras de crescimento de plantas (RPCP), capazes de promover efeito sinergístico na nodulação e no crescimento das plantas, pode representar uma alternativa para maximizar a eficiência da fixação de $\mathrm{N}$ e incrementar a produtividade da cultura. Dentre as rizobactérias utilizadas na inoculação de outras espécies leguminosas, se destacam as bactérias do gênero Azospirillum (CASSÁN et al., 2008; HUNGRIA \& NOGUEIRA, 2013). Neste contexto, iniciou-se, nos últimos anos no Brasil, os estudos com coinoculação de Bradyrhizobium sp. e Azospirillum brasilense nas culturas de soja e de feijão, buscando ganhos em nodulação, suprimento de $\mathrm{N}$ e maior produtividade de grãos (HUNGRIA et al., 2013). Nos casos em que se tem utilizado $A$. brasilense em leguminosas, os efeitos benéficos da associação com o Bradyrhizobium se devem, na maior parte, a capacidade que a rizobactéria tem de fixar $\mathrm{N}_{2}$ atmosférico (HUERGO et al., 2008), produzir hormônios vegetais (BOTTINI et al., 1989), aumentar a atividade da enzima nitrato redutase (CASSÁN et al., 2008) e solubilizar fosfato do solo (INAGAKI et al., 2014). Em geral, tem sido relatado que as RPCP beneficiam o crescimento e o desenvolvimento das plantas por uma combinação de todos esses mecanismos (DOBBELAERE et al., 2003). No entanto, não há estudos que comprovam os efeitos benéficos da coinoculação de bactéria dos gêneros Bradyrhizobium e Azospirillum na cultura do amendoim.

O presente estudo teve como objetivo avaliar os efeitos da coinoculação das sementes com Bradyrhizobium japonicum e Azospirillum brasilense e da aplicação de molibdênio na nodulação, no crescimento e na partição de matéria seca das plantas de amendoim (Arachis hypogaea L., cv. IAC Tatu ST), cultivadas em um solo arenoso do Cerrado.

\section{Material e Métodos}

O experimento foi realizado em casa de vegetação na Estação Experimental Agronômica da Universidade Estadual de Mato Grosso do Sul - UEMS, em

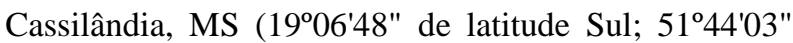
de longitude Oeste e altitude média de $470 \mathrm{~m}$ ), no período de dezembro de 2016 a fevereiro de 2017. Foram utilizados vasos plásticos com 5,5 L de capacidade, preenchidos com 5,0 L de solo arenoso peneirado em malha de $5 \mathrm{~mm}$, proveniente da camada superficial de $0,0-0,20 \mathrm{~m}$ de um Neossolo Quartzarênico, apresentando $\mathrm{pH}$ em $\mathrm{CaCl}_{2}=5,6$, matéria orgânica $=14 \mathrm{~g} \mathrm{dm}^{-3}, \mathrm{P}($ Mehlich-1) $=8,3 \mathrm{mg}$ $\mathrm{dm}^{-3}, \mathrm{~K}=0,07 \mathrm{cmol}_{\mathrm{c}} \mathrm{dm}^{-3}, \mathrm{Ca}^{2+},=2,00 \mathrm{cmol}_{\mathrm{c}} \mathrm{dm}^{-3}, \mathrm{Mg}$ $=0,70 \mathrm{cmol}_{\mathrm{c}} \mathrm{dm}^{-3}, \mathrm{H}+\mathrm{Al}=2,00 \mathrm{cmol}_{\mathrm{c}} \mathrm{dm}^{-3}, \mathrm{CTC}=$ $4,80 \mathrm{cmol}_{\mathrm{c}} \mathrm{dm}^{-3}$ e $\mathrm{V}=58 \%$. O teor de Mo disponível no solo (extraído por solução de $1,0 \mathrm{~mol} \mathrm{~L}^{-1}$ de acetato de amônio) foi de $0,38 \mathrm{mg} \mathrm{dm}^{-3}$, que pode ser considerado de média disponibilidade para as plantas.

O solo foi fertilizado com $30 \mathrm{mg} \mathrm{dm}^{-3}$ de $\mathrm{N}$ (ureia), $250 \mathrm{mg} \mathrm{dm}^{-3}$ de P (superfosfato simples), $80 \mathrm{mg} \mathrm{dm}^{-3}$ 
de $\mathrm{K}$ (cloreto de potássio), $2 \mathrm{mg} \mathrm{dm}^{-3}$ de $\mathrm{Cu}$ (sulfato de cobre), $2 \mathrm{mg} \mathrm{dm}^{-3}$ de $\mathrm{Zn}$ (sulfato de zinco) e $1 \mathrm{mg} \mathrm{dm}^{-3}$ de B (ácido bórico), seguindo as recomendações de Novais et al. (1991) para ensaios de vaso em condições controladas.

Os vasos foram dispostos em um delineamento de blocos ao acaso, com quatro repetições, tendo os tratamentos seguido a combinação fatorial $(2 \times 4)$, com a aplicação (+Mo) ou não de molibdênio ( $-\mathrm{Mo})$ na proporção de $10 \mathrm{~g} / 50 \mathrm{~kg}$ de semente associado a quatro tratamentos de inoculação das sementes [i) controle (sem inoculação); ii) inoculação com Bradyrhizobium japonicum; iii) inoculação com Azospirillum brasilense; e, iv) coinoculação com B. japonicum e A. brasilense].

A fonte de Mo utilizada foi o fertilizante comercial para sementes Nódulus ${ }^{\circledR}$ Premium 125 (Biosoja) contendo: $\mathrm{Mo}, 10 \%$; Co, $1 \%$; S, $1 \%$; Ca, $1 \%$; Fe, $0,2 \%$. A inoculação das sementes com Bradyrhizobium japonicum foi realizada com o inoculante comercial líquido Simbiose Nod Soja ${ }^{\circledR}$ (Simbiose: Agrotecnologia Biológica) contendo as estirpes SEMIA 5079 e SEMIA 5080 (concentração mínima de 7,2 x $10^{9}$ células viáveis por $\mathrm{mL}$ ), na dose de $150 \mathrm{~mL}$ para $50 \mathrm{~kg}$ de sementes. Para a inoculação com Azospirillum brasilense foi utilizado o inoculante comercial líquido AzoTotal ${ }^{\circledR}$ (Total Biotecnologia) que contém as estirpes AbV5 e AbV6 (concentração mínima de 2,0 x $10^{8}$ células viáveis por $\mathrm{mL}$ ), na dose de $200 \mathrm{~mL}$ para $50 \mathrm{~kg}$ de sementes. A coinoculação foi realizada misturando as duas rizobactérias, nas mesmas proporções utilizadas quando inoculadas isoladamente, ou seja, $150 \mathrm{~mL}$ do inoculante contendo B. japonicum $+200 \mathrm{~mL}$ de inoculante contendo $A$. brasilense para $50 \mathrm{~kg}$ de sementes de amendoim. As quantidades de inoculantes utilizadas foram dissolvidas em uma solução contendo 2 $\mathrm{mL} / \mathrm{kg}$ de semente de aditivo para inoculante Protege ${ }^{\circledR}$ TS (Total Biotecnologia) e, então, ambos os produtos (inoculante + aditivo) foram aplicadas nas sementes 30 minutos após a aplicação de Mo. O aditivo para inoculante é constituído de metabólitos ativos de bactérias, complexo de açúcares e biopolímeros encapsulantes e tem a finalidade de melhorar a proteção e a viabilidade das bactérias sobre as sementes.

A semeadura foi realizada no dia 30/12/2016, utilizando-se o cultivar IAC Tatu ST de porte ereto, ciclo precoce de 90 a 100 dias, e peso médio de 100 grãos de 40-46 g. Foram semeadas 10 sementes por vaso, e aos oito dias após a semeadura, realizou-se o desbaste deixando-se duas plantas por vaso. O teor de água do solo foi monitorado diariamente e mantido próximo da capacidade de retenção de água com irrigações diárias pelo sistema de microaspersão.

A temperatura e a umidade relativa do ar foram monitoradas diariamente com o auxílio de um Data Logger modelo ITLOG-80 (Instrutemp Instrumentos de
Medição Ltda, São Paulo, SP, BRA) instalado dentro da casa de vegetação. As condições ambientais durante a condução do experimento foram: temperaturas mínima e máxima do ar de 19,4 e $37,6{ }^{\circ} \mathrm{C}$, respectivamente, e umidade relativa média de $78 \%( \pm 6 \%)$.

Durante a fase de estabelecimento das plantas, o número de plântulas emergidas foi mensurado diariamente até o $12^{\circ}$ dia após a semeadura, e com os valores contabilizados, foram calculados a porcentagem de emergência (\%), o índice de velocidade de emergência (IVE) e o tempo médio de emergência (TME).

O IVE foi calculado utilizando-se a equação proposta por Maguire (1962): $\operatorname{IVE}=\left(\mathrm{E}_{1} / \mathrm{N}_{1}\right)+\left(\mathrm{E}_{2} / \mathrm{N}_{2}\right)+$ $\left(\mathrm{E}_{3} / \mathrm{N}_{3}\right)+\ldots+\left(\mathrm{E}_{\mathrm{n}} / \mathrm{N}_{\mathrm{n}}\right)$, onde, IVE $=$ índice de velocidade de emergência (plântulas dia ${ }^{-1}$ ); $\mathrm{E}_{1}, \mathrm{E}_{2}, \mathrm{E}_{3}, \ldots$, En = número de plântulas emergidas computadas na primeira, segunda, terceira e última contagem; e, $\mathrm{N}_{1}, \mathrm{~N}_{2}, \mathrm{~N}_{3}, \ldots$, $\mathrm{N}_{\mathrm{n}}$ = número de dias da semeadura à primeira, segunda, terceira e última contagem. O TME foi calculado através da proposta por Labouriau (1983): TME $=\Sigma$ $\left(\mathrm{n}_{\mathrm{i}} \mathrm{t}_{\mathrm{i}}\right) / \Sigma \mathrm{n}_{\mathrm{i}}$, onde, TME = tempo médio de emergência (dias); $\mathrm{n}_{\mathrm{i}}=$ número de plântulas emergidas no intervalo entre cada contagem; $\mathrm{e}, \mathrm{t}_{\mathrm{i}}=$ tempo decorrido entre $\mathrm{o}$ início da emergência e a i-ésima contagem.

Aos 40 dias após a semeadura, no início do florescimento do amendoim, as plantas foram colhidas e as seguintes variáveis mensuradas: número de folhas (NF), contando-se todas as folhas desenvolvidas presentes na planta; número de hastes por planta $(\mathrm{NH})$, contando-se o número total de hastes das plantas; altura de planta (AP), medindo-se a haste principal do colo até o meristema apical com o auxílio de régua graduada em centímetro $(\mathrm{cm})$; número de nódulos $(\mathrm{NN})$, obtido pela contagem do número de nódulos presentes nas raízes. Em seguida, os nódulos foram destacados e colocados em estufa por 48 horas à $65^{\circ} \mathrm{C}$ com pesagem do material seco em balança analítica com precisão de 0,0001 g e, então, calculado a razão entre a massa de matéria seca dos nódulos e o número de nódulos para obter-se a massa de matéria seca média por nódulo.

O volume radicular (VR) foi determinado pelo método de deslocamento de água, utilizando uma proveta de $100 \mathrm{~mL}$ graduada em mililitros (mL), portanto, com precisão de $\pm 1,0 \mathrm{~cm}^{3}$. A área foliar (AF) foi determinada seguindo metodologia proposta por Benincasa (2003), com modificações. Após a separação de todas as folhas das plantas, foram retirados 10 discos foliares de área conhecida $\left(2,0 \quad \mathrm{~cm}^{2}\right)$, que foi considerada a área foliar da amostra $\left(\mathrm{AF}_{\mathrm{Amostra}}\right)$. Em seguida, após a secagem em estufa de circulação forçada de ar, a temperatura de $65^{\circ} \mathrm{C}$, até atingirem massa constante, foi determinada a massa seca da amostra $\left(\mathrm{MS}_{\mathrm{Amostra}}\right)$ e a massa de matéria seca das folhas 
(MSF). A área foliar total (AF) foi obtida através da seguinte equação:

$$
\mathrm{AF}=\left[\left(\mathrm{AF}_{\text {Amostra }} \times \mathrm{MSF}\right) / \mathrm{MS}_{\text {Amostra }}\right] .
$$

Para a mensuração da massa de matéria seca das folhas (MSF), do caule (MSC) e das raízes (MSR), as plantas foram seccionadas em folha, caule e raiz e, em seguida, acondicionadas em sacos de papel, colocadas para secar em estufa de circulação de ar forçada com temperatura de $65{ }^{\circ} \mathrm{C}$ por $72 \mathrm{~h}$ e, então, pesadas em balança analítica com precisão de 0,0001 $\mathrm{g}$, sendo os resultados expressos em g/planta. A massa de matéria seca da parte aérea (MSPA) foi obtida com a soma da massa seca das folhas com a massa seca do caule, e a massa de matéria seca total (MST) foi obtida com a somatória de todas as partes da planta (folhas, caule e raízes). A relação entre a matéria seca das raízes e da parte aérea (MSR/MSPA), obtida através da divisão da massa seca da parte aérea pela massa seca das raízes.

A razão de área foliar (RAF), área foliar específica (AFE) e a razão de massa das folhas (RMF) foram determinadas a partir dos valores de área foliar (AF) expressos em $\mathrm{dm}^{2} /$ planta, massa de matéria seca total da planta (MST) e matéria seca das folhas (MSF), ambos expressos em g/planta, empregando-se as seguintes equações, de acordo com Benincasa (2003): [RAF = AF / MST], $[\mathrm{AFE}=\mathrm{AF} /$ $\mathrm{MSF}]$ e $[\mathrm{RMF}=\mathrm{MSF} / \mathrm{MST}]$.

Os dados foram submetidos à análise de variância e os efeitos significativos do teste $F(p=0,05)$ foram comparados pelo teste $\mathrm{t}$ (LSD), a $5 \%$ de probabilidade. As análises foram realizadas utilizando-se o software estatístico Sisvar versão 5.6 para Windows (Software de Análises Estatísticas, UFLA, Lavras, MG, BRA).

\section{Resultados e Discussão}

A aplicação de molibdênio (Mo) e a inoculação das sementes com Bradyrhizobium japonicum e Azospirillum brasilense de forma isolada ou combinada não afetou significativamente $(p>0,05)$ a porcentagem de emergência, o índice de velocidade de emergência e o tempo médio de emergência das plântulas de amendoim (Tabela 1). Estes resultados indicam que a aplicação de nutrientes e de bactérias simbióticas e associativas nas sementes não comprometeu o estabelecimento inicial do estande de plantas. O estabelecimento de um estande adequado de plantas é fundamental para obter altos níveis de rendimentos de grãos de amendoim.

A aplicação de Mo nas sementes de amendoim não influenciou significativamente $(p>0,05)$ o número e a massa de matéria seca dos nódulos (Tabela 2), o crescimento e a produção de matéria seca (Tabela 3 e 4). As respostas do amendoim à aplicação de Mo via sementes ou foliar, no Brasil, têm sido contraditórias e pouco consistentes, o que tem limitado o uso desta prática agrícola. Pesquisas realizadas em diferentes condições edafoclimáticas do Brasil têm reportado efeitos significativos em apenas algumas características isoladas da cultura, e que na maioria das vezes não resulta no aumento significativo da produtividade de amendoim ao molibdênio aplicado.

Caires e Rosolem (2000) constataram que a aplicação de Mo nas sementes aumentou a matéria seca de nódulos, mas não interferiu de forma significativa no número de nódulos, aos 74 dias após a emergência das plantas de amendoim. Quaggio et al. (2004) reportaram que o tratamento de sementes com Mo resultou nos maiores teores de $\mathrm{N}$ nas folhas de amendoim, proporcionando aumentos significativos na produtividade de grãos da cultura.

Em um solo arenoso do Cerrado, Trevisan et al. (2017) constataram que a adubação foliar de Mo melhorou a nodulação das raízes e a absorção de $\mathrm{N}$ das plantas de amendoim, no entanto, não teve efeitos significativos no crescimento e no rendimento de vagens e de grãos da cultura.

O Mo é importante na composição da molibdoferrodoxina (complexo Mo-Fe-S-proteína), que juntamente com a azotoferredoxina (complexo Fe-S-proteína) formam a enzima nitrogenase, capaz de catalisar a redução do $\mathrm{N}_{2}$ a amônia $-\mathrm{NH}_{3}$ (LOPES; LIMA, 2015) e, da enzima nitrato redutase, responsável pela redução do nitrato $\left(\mathrm{NO}_{3}{ }^{-}\right)$a nitrito $\left(\mathrm{NO}_{2}{ }^{-}\right)$(KERBAUY, 2012). Em geral, os estudos indicam que a resposta do amendoim à adição de Mo está relacionada com o pH do solo, sendo as maiores respostas obtidas em solos com $\mathrm{pH}$ inferior a 5,0 (MENGEL; KIRKBY, 2001). Neste contexto, Rosolem e Caires (1998), reportaram que a calagem tem sido considerada prática eficiente para o suprimento adequado de Mo, por torná-lo mais disponível às plantas, em consequência da elevação do $\mathrm{pH}$ do solo, que promove liberação de íons-Mo adsorvidos na superfície dos óxidos de ferro e alumínio. Portanto, a ausência de resposta significativa da aplicação de Mo nas sementes evidenciada neste estudo se deve ao valor do $\mathrm{pH}$ do solo ser superior a 5,5, o que resultou em níveis adequados de Mo para as plantas de amendoim. O teor de Mo no solo utilizado no experimento foi de $0,38 \mathrm{mg} \mathrm{dm}^{-3}$, que pode ser considerado de média disponibilidade para as plantas. 
Tabela 1. Efeitos da aplicação de molibdênio e da coinoculação das sementes com Bradyrhizobium japonicum e/ou Azospirillum brasilense na porcentagem de emergência, no índice de velocidade de emergência e no tempo médio de emergência das plântulas de amendoim (Arachis hypogaea L., cv. IAC Tatu ST), cultivadas em solo arenoso do Cerrado sob condições de casa de vegetação

\begin{tabular}{|c|c|c|c|}
\hline Fontes de variação & $\begin{array}{l}\text { Emergência de plântula } \\
(\%)\end{array}$ & $\begin{array}{l}\text { Índice de velocidade de emergência } \\
\text { (plântulas/dia) }\end{array}$ & $\begin{array}{l}\text { Tempo médio de emergência } \\
\text { (dias) }\end{array}$ \\
\hline \multicolumn{4}{|l|}{ Aplicação de Molibdênio } \\
\hline$-\mathrm{Mo}$ & $91 \mathrm{a}$ & $1,71 \mathrm{a}$ & $5,56 \mathrm{a}$ \\
\hline$+\mathrm{Mo}$ & $92 \mathrm{a}$ & $1,75 \mathrm{a}$ & $5,39 \mathrm{a}$ \\
\hline \multicolumn{4}{|l|}{ Tratamento de Inoculação } \\
\hline Controle & $94 \mathrm{a}$ & $1,81 \mathrm{a}$ & $5,36 \mathrm{a}$ \\
\hline Bradyrhizobium japonicum & $88 \mathrm{a}$ & $1,64 \mathrm{a}$ & $5,58 \mathrm{a}$ \\
\hline Azospirillum brasilense & $90 \mathrm{a}$ & $1,65 \mathrm{a}$ & $5,68 \mathrm{a}$ \\
\hline B. japonicum + A. brasilense & $95 \mathrm{a}$ & $1,80 \mathrm{a}$ & $5,28 \mathrm{a}$ \\
\hline \multicolumn{4}{|l|}{$\begin{array}{l}\text { D. Japoncum + A. Drasuense } \\
\text { Teste F }\end{array}$} \\
\hline Bloco & $1,43^{\mathrm{NS}}$ & $0,46^{\mathrm{NS}}$ & $0,54^{\mathrm{NS}}$ \\
\hline Molibdênio (Mo) & $0,05^{\mathrm{NS}}$ & $0,45^{\mathrm{NS}}$ & $0,91^{\mathrm{NS}}$ \\
\hline Inoculação (I) & $2,40^{\mathrm{NS}}$ & $2,90^{\mathrm{NS}}$ & $1,14^{\mathrm{NS}}$ \\
\hline Interação $($ Mo × I) & $1,43^{\mathrm{NS}}$ & $1,41^{\mathrm{NS}}$ & $0,35^{\mathrm{NS}}$ \\
\hline $\mathrm{CV}(\%)$ & 8,48 & 10,06 & 9,14 \\
\hline
\end{tabular}

Tabela 2. Efeitos da aplicação de molibdênio e da coinoculação das sementes com Bradyrhizobium japonicum e/ou Azospirillum brasilense no número de nódulos, na matéria seca de nódulos e na matéria seca média por nódulo das plantas de amendoim (Arachis hypogaea L., cv. IAC Tatu ST) cultivadas em solo arenoso do Cerrado sob condições de casa de vegetação

\begin{tabular}{|c|c|c|c|}
\hline Fontes de variação & $\begin{array}{c}\text { Nódulos por planta } \\
\left(\mathrm{n}^{\circ} .\right)\end{array}$ & $\begin{array}{l}\text { Matéria seca de nódulos } \\
\left(\mathrm{mg} \mathrm{planta}^{-1}\right)\end{array}$ & $\begin{array}{l}\text { Matéria seca média por nódulo } \\
\left(\mathrm{mg} \mathrm{nódulo}^{-1}\right)\end{array}$ \\
\hline \multicolumn{4}{|l|}{ Aplicação de Molibdênio } \\
\hline$-\mathrm{Mo}$ & $168 \mathrm{a}$ & $97 \mathrm{a}$ & $3,42 \mathrm{a}$ \\
\hline$+\mathrm{Mo}$ & $188 \mathrm{a}$ & $101 \mathrm{a}$ & $3,74 \mathrm{a}$ \\
\hline \multicolumn{4}{|l|}{ Tratamento de Inoculação } \\
\hline Controle & $102 \mathrm{~b}$ & $68 \mathrm{~b}$ & $3,04 \mathrm{a}$ \\
\hline Bradyrhizobium japonicum & $109 \mathrm{~b}$ & $63 \mathrm{~b}$ & $3,75 \mathrm{a}$ \\
\hline Azospirillum brasilense & $131 \mathrm{~b}$ & $74 \mathrm{~b}$ & $3,51 \mathrm{a}$ \\
\hline B. japonicum + A. brasilense & $372 \mathrm{a}$ & $191 \mathrm{a}$ & $4,01 \mathrm{a}$ \\
\hline Teste F & & Valor de F & \\
\hline Bloco & $7,86^{*}$ & $4,47 *$ & $0,06^{\mathrm{NS}}$ \\
\hline Molibdênio (Mo) & $1,42^{\mathrm{NS}}$ & $0,28^{\mathrm{NS}}$ & $0,58^{\mathrm{NS}}$ \\
\hline Inoculação (I) & $27,77 * *$ & $16,88 * *$ & $1,08^{\mathrm{NS}}$ \\
\hline Interação $($ Mo × I) & $2,38^{\mathrm{NS}}$ & $3,14^{\mathrm{NS}}$ & $0,18^{\mathrm{NS}}$ \\
\hline $\mathrm{CV}(\%)$ & 19,71 & 21,78 & 13,75 \\
\hline
\end{tabular}

Snedecor. CV: coeficiente de variação.

A coinoculação das sementes com $B$. japonicum e $A$. brasilense influenciou significativamente $(\mathrm{p}<0,05) \mathrm{o}$ número de nódulos por planta e a matéria seca de nódulos por planta, mas não interferiu de forma significativa no tamanho dos nódulos radiculares das plantas de amendoim (Tabela 2). Os resultados reportaram que a inoculação combinada de $B$. japonicum e A. brasilense resultou no aumento de $265 \%$ no número de nódulos por planta e de $181 \%$ na matéria seca de nódulos por planta em comparação ao tratamento controle (sem inoculação). O maior número de nódulos por planta obtido com a coinoculação das sementes com $B$. japonicum e A. brasilense pode ter sido devido ao efeito sinergístico destas duas rizobactérias em melhorar a capacidade da formação dos nódulos radiculares em plantas leguminosas. Os efeitos benéficos da associação de bactérias simbióticas do gênero Bradyrhizobium com as bactérias associativas do gênero Azospirillum em plantas leguminosas se devem, na maior parte, à capacidade destas rizobactérias em fixar $\mathrm{N}_{2}$ atmosférico, produzir hormônios vegetais, aumentar a atividade da enzima nitrato redutase e solubilizar fosfato do solo (BOTTINI et al., 1989; CASSÁN et al., 2008; HUERGO et al., 2008; INAGAKI et al., 2014).

Santos et al. (2014) avaliando o efeito da inoculação de diferentes estirpes de rizóbio no crescimento inicial do amendoim cv. IAC Tatu ST, verificaram que a inoculação das sementes resultou no aumento do número de nódulos e na matéria seca de nódulos por planta. Por sua vez, Santos et al. (2005) avaliando diferentes isolados de rizóbios nativos da região nordeste do Brasil, verificaram que a quantidade e o tamanho dos nódulos por planta foram muito 
dependentes do cultivar e do isolado utilizado. A cultura do amendoim pode estabelecer simbiose com várias estirpes do gênero Rhizobium sp. e Bradyrhizobium sp. No entanto, para aumentar a eficiência da inoculação é de fundamental importância que as estirpes do inoculante tenha elevada capacidade de competir com as estirpes nativas de rizóbios do solo.

A inoculação das sementes com $B$. japonicum e $A$. brasilense de forma isolada não se revelou como prática agronômica eficiente, por resultar em capacidade de nodulação semelhante ao tratamento controle, sem inoculação (Tabela 2). Veronezi et al. (2012) observaram resultados semelhantes avaliando diferentes estirpes de Rhizobium sp. e A. brasilense na cultura do feijoeiro; a coinoculação das sementes com o isolado CPAO 19.5 L3 em associação as estirpes Ab-V5 e AbV6 de A. brasilience resultou em maior nodulação radicular das plantas em comparação às sementes inoculadas com estas estirpes de forma isolada.

A inoculação das sementes com B. japonicum e $A$. brasilense de forma isolada e combinada influenciou significativamente $(\mathrm{p}<0,05)$ a altura das plantas, o número de folhas e a área foliar das plantas, mas não interferiu de forma significativa $(\mathrm{p}>0,05)$ no número de hastes por planta e no volume radicular das plantas de amendoim (Tabela 3). A coinoculação das sementes com as duas rizobactérias resultou em plantas com maior altura e área foliar, indicando que a inoculação combinada de $B$. japonicum e A. brasilense melhorou o crescimento das plantas de amendoim (Tabela 3). A coinoculação das sementes com $B$. japonicum e $A$. brasilense de forma combinada resultou nos maiores valores de matéria seca da parte aérea e total em comparação aos demais tratamentos (Tabela 4).

Os resultados demonstrados na Tabela 4 reportam que a coinoculação destas duas rizobactérias pode ser um fator determinante para o melhor crescimento e desenvolvimento das plantas de amendoim em solos arenosos da região do Cerrado. $\mathrm{O}$ aumento do crescimento das plantas de amendoim com a coinoculação das sementes pode estar relacionado aos benefícios oriundos da coinoculação, por meio da associação da capacidade de fixação de $\mathrm{N}_{2}$ pelas bactérias com $B$. japonicum com a produção de hormônios vegetais das bactérias A. brasilense. Segundo Bárbaro et al. (2009), a coinoculação consiste na utilização de combinações de diferentes microorganismos, os quais produzem um efeito sinérgico superando os resultados produtivos obtidos com os mesmos, quando em forma isolada. Cabe salientar, que entre os hormônios vegetais, as estirpes de A. brasilense têm capacidade de produzir auxinas, giberelinas, citocininas em condições "in vitro" (MASCIARELLI et al., 2013).

A inoculação das sementes com $B$. japonicum e $A$. brasilense de forma isolada e combinada não afetou significativamente $(\mathrm{p}>0,05)$ o desenvolvimento do sistema radicular das plantas de amendoim, como evidenciado para o volume radicular (Tabela 3) e matéria secas das raízes (Tabela 4).

Tabela 3. Efeitos da aplicação de molibdênio e da coinoculação das sementes com Bradyrhizobium japonicum e/ou Azospirillum brasilense na altura das plantas, no número de hastes por planta, no número de folhas por planta, na área foliar e no volume radicular das plantas de amendoim (Arachis hypogaea L., cv. IAC Tatu ST) cultivadas em solo arenoso do Cerrado sob condições de casa de vegetação

\begin{tabular}{|c|c|c|c|c|c|}
\hline Fontes de variação & $\begin{array}{l}\text { Altura de planta } \\
(\mathrm{cm})\end{array}$ & $\begin{array}{l}\text { Haste por planta } \\
\left(\mathrm{n}^{\circ} .\right)\end{array}$ & $\begin{array}{c}\text { Folhas por planta } \\
\left(\mathrm{n}^{\circ} .\right)\end{array}$ & $\begin{array}{c}\text { Área foliar } \\
\left(\mathrm{dm}^{2} \text { planta }^{-1}\right)\end{array}$ & $\begin{array}{l}\text { Volume radicular } \\
\left(\mathrm{cm}^{3} \text { planta }^{-1}\right)\end{array}$ \\
\hline \multicolumn{6}{|l|}{ Aplicação de Molibdênio } \\
\hline$-\mathrm{Mo}$ & $15,2 \mathrm{a}$ & $3,84 \mathrm{a}$ & $27,9 \mathrm{a}$ & $85,5 \mathrm{a}$ & $15,0 \mathrm{a}$ \\
\hline$+\mathrm{Mo}$ & $16,9 \mathrm{a}$ & $4,16 \mathrm{a}$ & $29,5 \mathrm{a}$ & $90,5 \mathrm{a}$ & $13,7 \mathrm{a}$ \\
\hline \multicolumn{6}{|l|}{ Tratamento de Inoculação } \\
\hline Controle & $14,4 \mathrm{~b}$ & $4,12 \mathrm{a}$ & $27,7 \mathrm{~b}$ & \multirow{4}{*}{$\begin{array}{r}73,8 \mathrm{~b} \\
67,9 \mathrm{~b} \\
84,0 \mathrm{~b} \\
126,4 \mathrm{a}\end{array}$} & $14,9 \mathrm{a}$ \\
\hline Bradyrhizobium japonicum & $12,8 \mathrm{c}$ & $3,69 \mathrm{a}$ & $25,6 \mathrm{~b}$ & & $13,1 \mathrm{a}$ \\
\hline Azospirillum brasilense & $15,8 \mathrm{~b}$ & $3,81 \mathrm{a}$ & $27,4 \mathrm{~b}$ & & $14,6 \mathrm{a}$ \\
\hline B. japonicum + A. brasilense & $21,4 \mathrm{a}$ & $4,37 \mathrm{a}$ & $34,1 \mathrm{a}$ & & $14,6 \mathrm{a}$ \\
\hline \multicolumn{3}{|l|}{ Teste F } & Valor de F & \multirow{3}{*}{$\begin{array}{l}1,78^{\mathrm{NS}} \\
0,52^{\mathrm{NS}}\end{array}$} & \\
\hline Bloco & $2,45^{\mathrm{NS}}$ & $2,80^{\mathrm{NS}}$ & $1,81^{\mathrm{NS}}$ & & $2,07^{\mathrm{NS}}$ \\
\hline Molibdênio (Mo) & $3,56^{\mathrm{NS}}$ & $2,39^{\mathrm{NS}}$ & $0,74^{\mathrm{NS}}$ & & $3,29^{\mathrm{NS}}$ \\
\hline Inoculação (I) & $17,54 * *$ & $2,39^{\mathrm{NS}}$ & $5,90 * *$ & \multirow{2}{*}{$\begin{array}{c}14,66^{* *} \\
2,59^{\mathrm{NS}}\end{array}$} & $1,31^{\mathrm{NS}}$ \\
\hline Interação $($ Mo × I) & $1,48^{\mathrm{NS}}$ & $1,79^{\mathrm{NS}}$ & $3,02^{\mathrm{NS}}$ & & $1,79^{\mathrm{NS}}$ \\
\hline $\mathrm{CV}(\%)$ & 7,49 & 6,48 & 7,51 & 10,99 & 5,73 \\
\hline
\end{tabular}


Os resultados indicam que a inoculação de bactérias simbióticas e associativas não interfere no crescimento das raízes de amendoim em condições de casa de vegetação. Resultados semelhantes foram reportados por Zuffo et al. (2015), os quais avaliaram a inoculação de A. brasilense isoladamente ou em coinoculação com Bradyrhizobium japonicum na cultura da soja, e verificaram que não houve efeito significativo da inoculação na matéria seca das raízes, matéria seca dos nódulos e no volume radicular.

$\mathrm{Na}$ Tabela 5 constam os valores dos índices morfofisiológicos das plantas de amendoim aos 40 dias após a semeadura em função da aplicação de Mo e da inoculação das sementes com $B$. japonicum e $A$. brasilense de forma isolada ou combinada. A aplicação de Mo nas sementes não influenciou significativamente ( $\mathrm{p}>0,05$ ) nenhum dos índices morfofisiológicos das plantas. A coinoculação com $B$. japonicum e $A$. brasilense de forma combinada influenciou significativamente $(\mathrm{p}<0,05)$ a razão de área foliar (RAF) e a razão de massa das folhas (RMF), mas não interferiu de forma significativa $(\mathrm{p}>0,05)$ na área foliar específica (AFE) das plantas de amendoim (Tabela 5).

Tabela 4. Efeitos da aplicação de molibdênio e da coinoculação das sementes com Bradyrhizobium japonicum e/ou Azospirillum brasilense na produção de matéria seca da parte aérea, das raízes e total e na relação da matéria seca das raízes: parte aérea das plantas de amendoim (Arachis hypogaea L., cv. IAC Tatu ST) cultivadas em solo arenoso do Cerrado sob condições de casa de vegetação.

\begin{tabular}{|c|c|c|c|c|}
\hline Fontes de variação & $\begin{array}{l}\text { Matéria seca da parte aérea } \\
\left(\mathrm{g} \text { planta }^{-1}\right)\end{array}$ & $\begin{array}{l}\text { Matéria seca das raízes } \\
\left(\mathrm{g}_{\text { planta }}^{-1}\right)\end{array}$ & $\begin{array}{l}\text { Matéria seca total } \\
\left(\mathrm{g}_{\text { planta }}^{-1}\right)\end{array}$ & $\begin{array}{c}\text { Relação raiz: parte aérea } \\
\left(\mathrm{g} \mathrm{g}^{-1}\right)\end{array}$ \\
\hline \multicolumn{5}{|l|}{ Aplicação de Molibdênio } \\
\hline$-\mathrm{Mo}$ & $3,26 \mathrm{a}$ & $1,32 \mathrm{a}$ & $4,58 \mathrm{a}$ & $0,436 \mathrm{a}$ \\
\hline +Mo & $3,58 \mathrm{a}$ & $1,30 \mathrm{a}$ & $4,88 \mathrm{a}$ & $0,397 \mathrm{a}$ \\
\hline \multicolumn{5}{|l|}{ Tratamento de Inoculação } \\
\hline Controle & $2,89 \mathrm{~b}$ & $1,21 \mathrm{a}$ & $4,10 \mathrm{~b}$ & $0,435 \mathrm{~b}$ \\
\hline Bradyrhizobium japonicum & $2,59 \mathrm{~b}$ & $1,28 \mathrm{a}$ & $3,87 \mathrm{~b}$ & $0,505 \mathrm{a}$ \\
\hline Azospirillum brasilense & $3,31 \mathrm{~b}$ & $1,26 \mathrm{a}$ & $4,56 \mathrm{~b}$ & $0,424 b$ \\
\hline B. japonicum + A. brasilense & $4,91 \mathrm{a}$ & $1,48 \mathrm{a}$ & $6,39 \mathrm{a}$ & $0,303 \mathrm{c}$ \\
\hline Teste F & \multicolumn{4}{|c|}{ Valor de F } \\
\hline Bloco & $2,10^{\mathrm{NS}}$ & $1,99^{\mathrm{NS}}$ & $2,34^{\mathrm{NS}}$ & $1,45^{\mathrm{NS}}$ \\
\hline Molibdênio (Mo) & $1,73^{\mathrm{NS}}$ & $0,04^{\mathrm{NS}}$ & $1,06^{\mathrm{NS}}$ & $3,62^{\mathrm{NS}}$ \\
\hline Inoculação (I) & $16,89 * *$ & $2,63^{\mathrm{NS}}$ & $13,85^{* *}$ & $16,26 * *$ \\
\hline Interação $(\mathrm{Mo} \times \mathrm{I})$ & $2,40^{\mathrm{NS}}$ & $0,34^{\mathrm{NS}}$ & $2,68^{\mathrm{NS}}$ & $2,97^{\mathrm{NS}}$ \\
\hline $\mathrm{CV}(\%)$ & 8,98 & 5,78 & 8,24 & 14,12 \\
\hline
\end{tabular}

Tabela 5. Efeitos da aplicação de molibdênio e da coinoculação das sementes com Bradyrhizobium japonicum e/ou Azospirillum brasilense na razão de área foliar (RAF), área foliar específica (AFE) e a razão de massa das folhas (RMF) das plantas de amendoim (Arachis hypogaea L., cv. IAC Tatu ST) cultivadas em solo arenoso do Cerrado sob condições de casa de vegetação

\begin{tabular}{|c|c|c|c|}
\hline Fontes de variação & $\begin{array}{l}\text { Razão de área foliar } \\
\qquad\left(\mathrm{dm}^{2} \mathrm{~g}^{-1}\right)\end{array}$ & $\begin{array}{l}\text { Área foliar específica } \\
\left(\mathrm{dm}^{2} \mathrm{~g}^{-1}\right)\end{array}$ & $\begin{array}{l}\text { Razão de massa das folhas } \\
\qquad\left(\mathrm{g} \mathrm{g}^{-1}\right)\end{array}$ \\
\hline \multicolumn{4}{|l|}{ Aplicação de Molibdênio } \\
\hline$-\mathrm{Mo}$ & $0,184 \mathrm{a}$ & $0,450 \mathrm{a}$ & $0,408 \mathrm{a}$ \\
\hline$+\mathrm{Mo}$ & $0,182 \mathrm{a}$ & $0,445 \mathrm{a}$ & $0,408 \mathrm{a}$ \\
\hline \multicolumn{4}{|l|}{ Tratamento de Inoculação } \\
\hline Controle & $0,179 \mathrm{~b}$ & $0,449 \mathrm{a}$ & $0,393 \mathrm{c}$ \\
\hline Bradyrhizobium japonicum & $0,173 \mathrm{~b}$ & $0,452 \mathrm{a}$ & $0,387 \mathrm{c}$ \\
\hline Azospirillum brasilense & $0,181 \mathrm{~b}$ & 0,439 a & $0,411 b$ \\
\hline B. japonicum + A. brasilense & $0,198 \mathrm{a}$ & $0,451 \mathrm{a}$ & $0,440 \mathrm{a}$ \\
\hline Teste F & & Valor de F & \\
\hline Bloco & $0,31^{\mathrm{NS}}$ & $0,55^{\mathrm{NS}}$ & $0,06^{\mathrm{NS}}$ \\
\hline Molibdênio (Mo) & $0,18^{\mathrm{NS}}$ & $0,34^{\mathrm{NS}}$ & $0,01^{\mathrm{NS}}$ \\
\hline Inoculação (I) & $5,06 * *$ & $0,43^{\mathrm{NS}}$ & $11,99 * *$ \\
\hline Interação $(\mathrm{Mo} \times \mathrm{I})$ & $3,18^{\mathrm{NS}}$ & $1,51^{\mathrm{NS}}$ & $2,79^{\mathrm{NS}}$ \\
\hline $\mathrm{CV}(\%)$ & 7,23 & 5,62 & 4,83 \\
\hline
\end{tabular}


A razão de área foliar (RAF) representa a área foliar total $\left(\mathrm{em} \mathrm{dm}^{2}\right)$ que está sendo usada pela planta para produzir 1,0 g de matéria seca (BENINCASA, 2003). O aumento da RAF com a coinoculação das sementes indica que houve maior conversão dos fotoassimilados em folhas, aumentando a captação da radiação solar disponível devido a maior área foliar (Tabela 3) e maior razão de massa das folhas - RMF (Tabela 5). Por outro lado, os menores valores nos demais tratamentos são decorrentes do auto-sombreamento, secamento e queda de folhas com o avanço do desenvolvimento da planta, como verificaram Urchei et al. (2000) em feijão.

A área foliar específica (AFE) relaciona a superfície e a massa da folha, representando a espessura desta. Portanto, considerando que a AFE representa o espessamento da folha (BENINCASA, 2003), a redução do índice indica o acúmulo de fotoassimilados pelas folhas (folhas mais espessas) para posterior translocação a outros órgãos da planta. Os resultados aqui apresentados indicam que a espessura da folha de amendoim se manteve constante independentemente da aplicação de Mo e da inoculação das sementes com $B$. japonicum e A. brasilense. Contudo, são necessários mais estudos com a cultura do amendoim para verificar se esta característica é inerente da espécie, ou se as condições climáticas proporcionaram essa característica do índice.

\section{Conclusões}

A aplicação de molibdênio nas sementes de amendoim não se mostrou uma prática agronômica eficaz para o cultivo da cultura em solos arenosos do Cerrado com $\mathrm{pH}$ superior a 5,5 por não afetar a nodulação, o crescimento, a partição de matéria seca e os índices morfofisiológicos das plantas.

A coinoculação das sementes com Bradyrhizobium japonicum e Azospirillum brasilense pode proporcionar sustentabilidade para o sistema de produção de amendoim na região do Cerrado por melhorar a nodulação das raízes, a fixação biológica de nitrogênio e o crescimento das plantas.

\section{Referências Bibliográficas}

BÁRBARO, I. M.; MACHADO, P. C.; BÁRBARO-JUNIOR, L. S.; TICELLI, M.; MIGUEL, F. B.; SILVA, J. A. A. Produtividade da soja em resposta à inoculação padrão e coinoculação. Colloquium Agrariae, Presidente Prudente-SP, v. 5, n. 1, p. 1-7, 2009.

BENINCASA, M. P. M. Análise de crescimento de plantas: noções básicas. Jaboticabal-SP: FUNEP, 2003, 41 p.

BOTTINI, R.; FULCHIERI, M.; PEARCE, D.; PHARIS, R. Identification of gibberelins A1, A3, and iso-A3 in cultures of
A. lipoferum. Plant Physiology, Amsterdam, v. 90, p. 45-47, 1989.

CAIRES, E. F.; ROSOLEM, C. A. Nodulação e absorção de nitrogênio pelo amendoim em resposta à calagem, cobalto e molibdênio. Scientia Agricola, Piracicaba-SP, v. 57, n. 2, p. 337-341, 2000.

CASSÁN, F.; SGROY, V.; PERRIG, D.; MASCIARELLI, O.; LUNA, V. Producción de fitohormonas por Azospirillum sp. Aspectos fisiológicos y tecnológicos de la promoción del crecimiento vegetal. In: CASSÁN, F. D.; SALAMONE, I. G. (Ed.) Azospirillum sp.: cell physiology, plant interactions and agronomic research in Argentina. Buenos Aires: Asociación Argentina de Microbiologia, 2008. p. 61-86.

CRUSCIOL, C. A. C.; SORATTO, R. P. Nutrição e produtividade do amendoim em sucessão ao cultivo de plantas de cobertura no sistema plantio direto. Pesquisa Agropecuária Brasileira, Brasília-DF, v. 42, n. 6, p. 1-8, 2007.

DOBBELAERE, S.; VANDERLEYDEN, J.; OKON, Y. Plant growth-promoting effects of diazotrophs in the rhizosphere. Critical Reviews in Plant Sciences, Amsterdam, v. 22, n. 2, p. 107-149, 2003.

HUERGO, L. F.; MONTEIRO, R. A.; BONATTO, A. C.; RIGO, L. U.; STEFFENS, M. B. R.; CRUZ, L. M.; CHUBATSU, L. S.; SOUZA, E. M.; PEDROSA, F. O. Regulation of nitrogen fixation in Azospirillum brasilense. In: CASSÁN, F. D.; GARCIA DE SALAMONE, I. Azospirillum sp.: cell physiology, plant interactions and agronomic research in Argentina. Buenos Aires: Asociación Argentina de Microbiologia, 2008. p.17-35.

HUNGRIA, M.; NOGUEIRA, M. A. Efeitos da coinoculação. Cultivar Grandes Culturas, Pelotas-RS, v. 170, n. 1, p. 40-41, 2013.

HUNGRIA, M.; NOGUEIRA, M. A.; ARAUJO, R. S. Coinoculation of soybeans and common beans with rhizobia and azospirilla: strategies to improve sustainability. Biology Fertility of Soils, Amsterdam, v. 49, n. 7, p. 791-801, 2013.

INAGAKI, A. M.; GUIMARÃES, V. F.; RODRIGUES, L. F. O. S.; SILVA, M. B.; DIAMANTE, M. S.; RAMPIM, L.; MIORANZA, T. M.; DUARTE JÚNIOR, J. B. Phosphorus fertilization associated to inoculation of maize with diazotrophic bacteria. African Journal of Agricultural Research, Lagos, v. 9, n. 48, p. 3480-3487, 2014.

KERBAUY, G. B. Fisiologia Vegetal. 2 ed. Rio de JaneiroRJ: Guanabara Koogan, 2012, 431 p.

LABOURIAU, L. G. A germinação de sementes. Washington: Organização dos Estados Americanos, 1983. 174 p.

LI, S. X.; WANG, Z. H.; STEWART, B. A. Chapter Five. Responses of Crop Plants to Ammonium and Nitrate N. Advances in Agronomy, Madson-USA, v. 118, n. 2, p. 205397, 2013.

LOPES, N. F.; LIMA, M. G. S. Fisiologia da produção. Viçosa-MG: Editora UFV. 2015. 492p. 
MAGUIRE, J. D. Speed of germination - aid in selectionand evaluation for seedling emergence and vigor. Crop Science, Madson-USA, v. n. 1, p. 2:176-177, 1962.

MASCIARELLI, O.; URBANI, L.; REINOSO, H.; LUNA, V. Alternative Mechanism for the Evaluation of Indole-3-Acetic Acid (IAA) Production by Azospirillum brasilense Strains and Its Effects on the Germination and Growth of Maize Seedlings. Journal Microbiology, New York-USA, v. 51, $\mathrm{n}$. 5, p. 590-597, 2013.

MENGEL, K.; KIRKBY, E. A. Principles of plant nutrition. $5^{\text {th }}$ edn. Dordrecht: Academic Publishers, Kluwer, 2001. 849p.

NOVAIS, R. F.; NEVES, J. C. L.; BARROS, N. F. Ensaio em ambiente controlado. In: OLIVEIRA, A. J. de; GARRIDO, W. E.; ARAÚJO, J. D.; LOURENÇO, S. (Coord.). Métodos de pesquisa em fertilidade do solo. Brasília-DF: Embrapa-SEA, 1991. p. 189-253. (Documentos, 3).

QUAGGIO, J. A.; GALLO, P. B.; OWINO-GERROH, C.; ABREU, M. F.; CANTARELLA, H. Peanut response to lime and molybdenum application in low $\mathrm{pH}$ soils. Revista Brasileira de Ciência do Solo, Viçosa-MG, v. 28, n. 4, p. 659-664, 2004.

ROSOLEM, C. A.; CAIRES, E. F. Yield and nitrogen uptake of peanuts as affected by lime, cobalt and molybdenum. Journal of Plant Nutrition, New York, v. 21, n. 4, p. 827 835, 1998.

SANTOS, C. E. R. S.; STAMFORD, N. P.; FREITAS, A. D. S. F.; VIEIRA, I. M. M. B.; SOUTO, S. M.; NEVES, M. C. P.; RUMJANEK, N. G. Efetividade de rizóbios isolados de solos da região Nordeste do Brasil na fixação do $\mathrm{N}_{2}$ em amendoim (Arachis hypogaea L.). Acta Scientiarum Agronomy, Maringá-PR, v. 27, n. 2, p. 301-307, 2005
SANTOS, C. C.; GUIMARÃES, S. L.; FARIAS, L. N.; BONFIM-SILVA, E. M.; POLIZEL, A. C. Crescimento inicial de plantas de amendoim inoculadas com rizóbio isolado de feijão caupi. Enciclopédia Biosfera: Centro Científico Conhecer, Goiânia-GO, v. 10, n. 18; p. 1097-1105, 2014.

THIES, J. E.; SINGLETON, P. W.; BOHLOOL B. B. Influence of the size of indigenous rhizobial populations on establishment and symbiotic performance of introduced rhizobia on field-grown legumes. Applied and Environmental Microbiology, Amsterdam, v. 57, n. 1, p. 19$28,1991$.

TREVISAN, M. V.; STEINER, F.; ZUFFO, A. M.; LIMEDE, A. C.; OLIVEIRA, C. E. S. Inoculação e aplicação foliar de molibdênio em amendoim cultivado em área de pastagem degradada. IN: ALFARO, A. T. S.; TROJAN, D. G. (Org.). Descobertas das Ciências Agrárias e Ambientais 2. Ponta Grossa-PR: Atena Editora, 2017. p. 214-233.

URCHEI, M. A.; RODRIGUES, J. D.; STONE, L. F. Análise de crescimento de duas cultivares de feijoeiro sob irrigação, em plantio direto e preparo convencional. Pesquisa Agropecuária Brasileira, Brasília-DF, v. 35, n. 3, p. 497-506, 2000.

VERONEZI, S. D. F.; COSTA, M. R.; SILVA, A. T.; MERCANTE, F. M. Co-inoculação de rizóbio e Azospirillum brasilense em feijoeiro (Phaseolus vulgaris L.). Cadernos de Agroecologia, Curitiba-PR, v. 7, n. 2, p. 1-4 2012.

ZUFFO, A. M.; REZENDE, P. M.; BRUZI, A. T.; OLIVEIRA, N. T.; SOARES, I. O.; NETO G. F. G.; CARDILlO, B. E. S.; SILVA, L. O. Co-inoculation of Bradyrhizobium japonicum and Azospirillum brasilense in the soybean crop. Revista de Ciências Agrarias, Lisboa, v. 38, n. 1, p. 87-93, 2015 